\title{
Feminismos como pontos de partilha: comunicação e saúde contra os silêncios
}

\section{Feminisms as sharing points: comunication and health against silences Feminismos como puntos de intercambio: comunicación y salud frente al silencio}

\section{Flavia Pinto Leiroz ${ }^{1, a}$}

flavialeiroz@gmail.com | https://orcid.org/oooo-0002-6761-466X

Patrícia Cardoso D’Abreu ${ }^{2, b}$

patriciadabreu@gmail.com | https://orcid.org/oooo-0002-4371-4615

\footnotetext{
${ }^{1}$ Universidade Federal do Rio de Janeiro, Escola de Comunicação e Cultura. Rio de Janeiro, RJ, Brasil.

2 Universidade Federal do Espírito Santo, Departamento de Comunicação. Vitória, ES, Brasil.

a Doutorado em Letras pela Pontifícia Universidade Católica do Rio de Janeiro.

${ }^{b}$ Doutorado em Comunicação pela Universidade Federal Fluminense.
}

Palavras-chave: Feminismos; Saúde das mulheres; Comunicação; Silenciamento; Estudos de gênero.

Keywords: Feminisms; Women’s health; Communication; Silencing; Gender studies.

Palabras clave: Feminismo; Salud de las mujeres; Comunicación; Silenciamiento; Estudios de género.

A saúde da mulher é concebida de maneira controversa. De forma restrita, o entendimento pelo viés da biologia e da anatomia do corpo aprisiona a mulher na função reprodutiva, limitando-se à saúde materna; de forma ampliada, dialoga com direitos humanos e cidadania, evocando questões de gênero que fomentam a luta por direitos sexuais e reprodutivos, e mostrando que saúde e doença são processos cujos contextos específicos dão a ver sociabilidades, diferenças de classe, fatores econômicos, práticas culturais e historicidades.

A dinâmica social das relações de gênero nos expõe a diferentes situações de sanidade, sofrimento, adoecimento, cura e morte. Isso explicita a fundamental importância que o pensamento feminista tem no campo da saúde ao introduzir nas agendas das políticas públicas questões antes restritas ao privado e à intimidade. Incorporadas e amplificadas pela mídia, essas manifestações fazem uso da comunicação como estratégia para a transformação.

Delimitando campos de atuação e produzindo materialidades, diversos desequilíbrios e desigualdades de gênero se refletem na produção de discursos e representações postos a circular em diferentes linguagens e meios (D’ABREU; RIBEIRO, 2018). Mídia tradicional, redes sociais e plataformas digitais adensam a produção de sentidos dissonantes: ao mesmo tempo em que trazem à tona o controverso imaginário 
brasileiro em relação ao corpo da mulher, colocam em pauta as particularidades dos diferentes grupos populacionais de mulheres e os contextos nos quais elas estão inseridas.

Como padrões hegemônicos de feminilidade ainda são amplamente disseminados e ratificados nos espaços midiáticos, narrativas e imagens sobre as mulheres geram sofrimento. Assim, em sinergia com o pensamento feminista, ações e processos de comunicação são de fundamental importância para construção de redes de discussão e disseminação de informações que objetivem a conscientização cidadã. Pautados pelas lutas das mulheres por direitos civis, direito ao saber e à informação, direitos políticos, direitos ao trabalho e, fundamentalmente, direito ao próprio corpo, os feminismos estabelecem, a partir das singularidades das experiências interseccionais, espaços de multiplicidade e novos protagonismos, além da partilha de experiências e aspirações de transformação social.

Sob esta perspectiva, convocamos para esta edição da Revista Eletrônica de Comunicação, Informação \& Inovação em Saúde (Reciis) artigos originais nos quais pesquisas científicas sobre modos de viver, curar, adoecer e morrer das mulheres indagassem a relação entre feminismos, comunicação e informação em saúde. O resultado foram 27 submissões de textos, dos quais 12 se enquadravam na proposta editorial e mostraram-se estruturalmente e metodologicamente aptos, o que demandou a publicação deste dossiê em duas partes. Antes de abordarmos esta primeira, é preciso comentar os textos que não foram incluídos. A qualidade não foi o único critério de corte, mas também, e principalmente, a articulação com o pensamento feminista e com questões pertinentes ao campo da comunicação social e da saúde. Nesse sentido, percebemos certa tendência de sinonimizar o campo da comunicação com o campo da ciência da informação - o diálogo entre ambos pode ser profícuo, desde que observadas e apontadas suas intersecções. Dados estatísticos sobre violências cometidas contra mulheres, levantamentos sobre a qualidade do acolhimento nos serviços de saúde, perspectivas éticas de tratamentos culturalmente impostos, ativismos que questionam determinados paradigmas médicos relativos aos corpos femininos, imaginários aprisionantes e culto ao machismo emergiram de trabalhos de excelente qualidade, mas cuja perspectiva teórica não contemplou a linha editorial proposta.

Dizemos isso porque consideramos importante afirmar o 'não silenciamento' dessas pesquisas. Como bem aponta Rebecca Solnit (2017, p. 22), se "a história do silêncio é central na história das mulheres", é fundamental esclarecer que, feitas as considerações editorais pertinentes, colocamos esses trabalhos deliberadamente no estado de quietude, uma vez que não identificamos neles as vozes feministas ou os ecos da comunicação. Convidamos, portanto, os que aqui não estão a articularem suas relevantes perspectivas no empreendimento maior da sinergia com o pensamento feminista e os processos de comunicação. Como o silêncio é, segundo Solnit (2017), uma violência difusa, é preciso diferenciá-lo da quietude com potencial reflexivo.

É a partir disso que entendemos a importância dos feminismos como questionamento e da comunicação como estratégia de transformação no que diz respeito à saúde. Conhecendo o pensamento feminista em suas demandas históricas, torna-se possível identificar tanto a combinação de coerções (intimidação, isolamento, controle) individuais praticadas contra uma vítima de violência doméstica como o controle coercitivo institucional que pune aquelas que se desvencilham do assujeitamento de seus corpos e tentam se adonar de seu meio de reprodução. Instrumentalizando a comunicação, o resultado desse conhecimento, colocado estrategicamente em circulação, permite o deslocamento do senso comum para o senso crítico.

Ao sistematizar as diferentes lutas das mulheres no mundo moderno, a historiadora Michelle Perrot (2015) nos ajuda a entender como as 'ondas' feministas são gritos que, transformadores das estruturas ou defensores de conquistas prévias, furam os vários silenciamentos impostos às mulheres. "Podemos considerar a história dos direitos e a falta de direitos das mulheres como uma história do silêncio e do rompimento do silêncio", alerta Solnitt (2017, p. 24). No contexto atual, quando o conservadorismo 
ressentido irrompe violentamente contra 'tudo' o que 'não é' macho-cis-hétero-branco, emerge também a relevância do pensamento de Simone de Beauvoir (2009): sua perspectiva do negativo pode, então, ser entendida não como mero olhar binário para a questão das mulheres, mas sim como apurada crítica à imposição unívoca (e, portanto, silenciadora) de uma subjetividade e de uma lógica que (ainda) tornam urgentes questionamentos e ressignificações. É preciso experimentar as mulheres como seres livres e de exercício de direitos: deslocar o sentido de 'mulheres objeto' da reificação para a reflexão que reexistencializa e que faz de suas vozes, ação. Para isso, é fundamental compreender o que não é dito, o que é silenciado. Como fazê-lo?

Começamos pela compreensão de que o silêncio é como um mar de inauditos que cercam ilhas de produção de sentido bem mapeadas e pouco acidentadas. Dando um passo à frente nessa compreensão, entendemos que é preciso erodir esses territórios, redesenhá-los no constante e sistemático marulhar que reclama direitos. Chegamos ao ponto no qual é preciso amplificar este 'trabalho de reconfiguração' pela comunicação, que tem por princípio elementar, como diz Muniz Sodré, a construção do bem comum, que se materializa pela troca e produz valor social, cultural e político (SODRÉ, 2014).

Um ponto que é de partilha: como silenciar é um dos atos mais violentos contra a existência, toda vez que as mulheres exigem ser ouvidas estão também distribuindo riquezas e subvertendo relações de poder que adoecem e matam. Na paisagem sonora do marulhar das ondas feministas que insistentemente reconfiguram textos e contextos, a primeira parte do dossiê Feminismos: perspectivas em comunicação e informação em saúde reúne trabalhos que tratam de atravessar diferentes formas de silenciamento. Os artigos aqui publicados assumem posturas teórico-metodológicas que nos permitem enxergar e ouvir a colisão de estruturas, a interação simultânea de avenidas identitárias (GONZALEZ, 1984; CRENSHAW, 1989).

Começamos pelo silenciamento midiático que Rayza Sarmento, Paula Dornelas, Maria Ligia Ganacim Granado Rodrigues Elias e Amanda Rocha apontam em 'Zika vírus e microcefalia nos discursos de mulheres no jornalismo e no Facebook'. O trabalho, sobre a emergência sanitária da epidemia do Zika vírus, em 2015, chama a atenção para a fala pública das mulheres. Movidas empiricamente em duas direções, as autoras analisaram o silenciamento de mães e gestantes como fontes e apontaram suas estratégias de resistência através do compartilhamento de experiências. O fôlego do levantamento de 176 notícias publicadas no jornal Folha de S.Paulo não se ateve a mostrar que as mulheres foram ouvidas em apenas 25 textos, mas também ressaltam uma perversa dinâmica entre desigualdades, temores, estereotipização, direitos reprodutivos e luta. A série de constrangimentos provocada pela assimetria midiática entre vozes de homens e mulheres é analisada sob a perspectiva de Iris Marion Young, que assinala não só a injustiça dessas coerções como também a prática de silenciar seu combate.

É também na perspectiva da luta contra o cerceamento que se embasa o artigo 'Interseccionalidade e rupturas dos modos de vida pelos rompimentos de barragem: reflexões a partir de uma mídia em aderência'. Assinado por Simone Santos Oliveira, Sergio Portella e Laura Luna Katona, o texto sobre a violação de direitos sofrida pelas populações diretamente atingidas pelos rompimentos das barragens de Mariana e Brumadinho foca o elo menos visível dessa cadeia de violências: as mulheres. O trabalho investiga como as discriminações se aprofundam quando elas estão na condição de defensoras de direitos humanos e do meio ambiente. Assim, a partir da noção de mídia aderente, vozes e redes de solidariedade contra o capitalismo patriarcal que compromete a saúde das mulheres são contempladas a partir da crítica que Donna Haraway, Judith Butler e María Lugones fazem sobre os discursos limitadores de vidas e negadores de existências.

No artigo seguinte, 'Racismo cotidiano na política brasileira: xingamentos e ameaças contra a parlamentar negra Talíria Petrone e seu significado na herança colonial', a articulação entre existência e resistência evidencia a reação violenta contra as mulheres negras que desestabilizam os privilégios da branquitude hegemônica. As opressões de raça e gênero que insistem em silenciá-las nos espaços da política institucional 
engendram graves ameaças à integridade física e à saúde mental. Assim, sob a perspectiva de pensadoras do porte de Grada Kilomba, as autoras Carla Baiense Felix e Monique Paulla analisam o Instagram da deputada negra Talíria Petrone para apontar as permanências escravagistas e os riscos de adoecimento e morte de mulheres negras na realidade traumática e cotidiana da sociedade brasileira. O texto enfatiza a necessidade de ações efetivas para coibir crimes desse tipo e assegurar os direitos dessas mulheres.

As diferentes violências praticadas contra as mulheres são, no texto de Lais de Mello Rocio, Rafael Paes Henriques e Gabriela Santos Alves, direcionadas para os assédios sexuais e a cultura de estupro. Buscando em Eleieth Saffioti o entendimento de que a violência é a materialização de um controle social repressivo, o trabalho 'Bastidores da reportagem sobre assédios sexuais que gerou o \#MeToo: reflexões sobre o jornalismo com perspectiva de gênero' entrelaça epistemologia feminista e teoria crítica do jornalismo. A proposta dos autores é fomentar a discussão sobre a necessidade da perspectiva de gênero na produção de reportagens. Para isso, memórias, historiografias e experiências femininas não podem ser silenciadas, uma vez que o silenciamento perpetua efeitos psicológicos nefastos (como depressão e tentativas de suicídio) sofridos pelas vítimas do assédio.

Várias dessas perspectivas se encontram no inspirador ensaio de Paula Gorini Oliveira, 'Coletivo em Silêncio: o encontro que cria um corpo político e produz vida', que narra a experiência de observação participante da autora em um coletivo feminista de arte e educação, antipunitivista e contra o encarceramento. Ao reunir depoimentos, poesias e entrevistas de mulheres atingidas pelo sistema prisional e de justiça, a autora faz essas falas ressoarem e explicitarem estratégias de resistência através da comunicação e da expressão artística. Entendendo a saúde como articulada a aspectos sociais, culturais e históricos, que garantem a manutenção da vida, e não apenas a prevenção à enfermidade, a autora lança um olhar político para corpos historicamente estigmatizados como impotentes, inúteis e dispensáveis ao sistema social. Corpos que, apesar de silenciados e adoecidos de suas potências de se comunicar, resistem.

Entre os artigos publicados por meio da demanda de fluxo regular, temos um conjunto variado de textos sobre as relações entre comunicação, informação e saúde: evolução de sífilis em gestantes, experiências de saúde de mulheres a partir de rádio comunitária, relações entre internet e saúde mental, além de reflexões sobre liderança, informação e ciência relacionadas à pandemia de Covid-19. A pandemia, como não poderia deixar de ser, é tema do relato de experiência, do artigo de revisão e da nota de conjuntura, que analisa a desarticulação entre raça e gênero para o enfrentamento à pandemia no Brasil. Também nesta edição, Rose de Melo Rocha é entrevistada pelo jornalista Roberto Abib. A professora fala sobre sua trajetória, a percepção das diferenças entre as experiências de gênero e sexualidade e os modos de narrá-las, que estão na arte, no entretenimento e na cultura pop. Para ela, a disputa por visibilidades de corporalidades e dissidências sexuais e de gênero tem força estética e política e pode nos ajudar a projetar utopias, principalmente na negociação com espaços midiáticos. Os estudos de gênero, assim, são fundamentais para descolonizar o pensamento. Os textos deste número da Reciis e do dossiê nele contido mostram reflexões e práticas de comunicação que, no entrecruzamento de estruturas de raça, classe, gênero e conjunturas sociais brasileiras, constroem possibilidades de ações para produzir diferentes materialidades.

Judith Butler (2020) diz que o movimento de mostrar a violência dos processos de exclusão deve ser simultâneo ao de ressignificar termos e experiências para transformá-los em desafios e legitimidade. Racismo, homofobia e misoginia não são análogos ou paralelos; não são equivalentes nem abstrata nem estruturalmente. Há histórias específicas de construção e elaboração que devem ser observadas, mas partilham vetores de poder e normas que se exigem e se implantam reciprocamente para alcançar a própria articulação. Para Butler (2019), podemos desconstruir essas normas pelo caminho da subversão, com base no incessante processo de construção de identidades que ressignificam termos que variam no tempo e no espaço de vidas no mundo e escrevem outras 
histórias propondo re-existências. A abordagem feminista na comunicação e em seus processos é contribuição fundamental.

\section{REFERÊNCIAS}

BEAUVOIR, Simone. O segundo sexo. 2. ed. Rio de Janeiro: Nova Fronteira, 2009. 2 v.

BUTLER, Judith. Corpos que importam. São Paulo: n-1 edições, 2019.

BUTLER, Judith. Problemas de gênero. Rio de Janeiro: Civilização Brasileira, 2020.

CRENSHAW, Kimberlé. Mapping the margins: interseccionality, identity politics, and violence against women of color. Stanford Law Review, Stanford, v. 43, n. 6, p. 1241-1299, jul. 1991. DOI: https://doi. org/10.2307/1229039. Disponível em: https://www.jstor.org/stable/1229039. Acesso em: 28 jun. 2021.

D'ABREU, Patrícia Cardoso; RIBEIRO, Ana Paula Goulart (org.). Mulher, cultura e mídia: investigações sobre o feminino. Rio de Janeiro: Multifoco, 2018.

GONZALEZ, Lélia. Racismo e sexismo na cultura brasileira. Revista Ciências Sociais Hoje, São Paulo, v. 2, p. 233-244, 1984.

PERROT, Michelle. Minha história das mulheres. São Paulo: Contexto, 2015.

SODRÉ, Muniz. A ciência do comum: notas para o método comunicacional. Petrópolis, RJ: Vozes, 2014.

SOLNIT, Rebecca. A mãe de todas as perguntas: reflexões sobre os novos feminismos. São Paulo:

Companhia das Letras, 2017. 